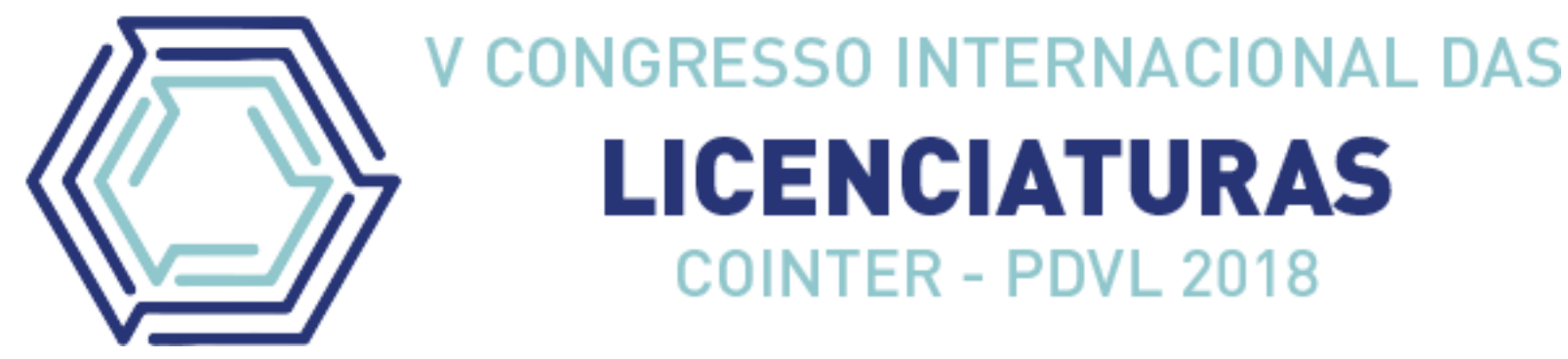

\title{
ESTRATÉGIAS DIDÁTICO-PEDAGÓGICO NO ENSINO DA GEOGRAFIA: CONSTRUINDO E REGIONALIZANDO A CIDADE DE TAIPU- RN SOB O OLHAR DO EDUCANDO
}

\section{DIDACTIC-PEDAGOGICAL STRATEGIES IN GEOGRAPHY EDUCATION: BUILDING AND REGIONALIZING THE CITY OF TAIPU- RN UNDER EDUCATION'S LOOK}

\author{
Apresentação: Comunicação Oral \\ ${ }^{1}$ João Paulo Teixeira Viana; ${ }^{2}$ Maria Cristina Cavalcanti Araújo \\ DOI: https://doi.org/10.31692/2358-9728.VCOINTERPDVL.2018.00074
}

\begin{abstract}
Resumo
Este estudo propõe como tema mostrar a importância das estratégias didático-pedagógico no ensino da geografia, através da atividade: construindo e regionalizando a cidade de Taipu- RN sob o olhar do educando. O intuito da pesquisa, além de elucidar essas estratégias no ensino da geografia escolar, está na construção de um projeto/aula que busca compreender o conceito de região, através da regionalização da cidade de Taipu - RN, mas a partir de imagens utilizando a vivência do aluno. Para o desenvolvimento do estudo, inicialmente foi realizada uma revisão bibliográfica, em seguida foi utilizado a metodologia "Pesquisa-ção" no decorrer da aplicação da estratégia na Escola Estadual Adão Marcelo da Rocha. Para se chegar aos resultados, foi preciso analisar a geografia atual sob uma perspectiva dos Parâmetros Curriculares Nacionais da Geografia (PCN), como também os desafios na educação atual; mostrar a importância das estratégias pedagógicas no ensino da geografia escolar e em seguida compreender a valorização do lugar como experiência humana e de vivência, e, por fim, o passo a passo da estratégia: regionalizando a cidade de Taipu-RN a partir de fotografias sob o olhar do educando. Como resultados da aplicação da estratégia, foi possível observar que os educandos passaram a compreender os conceitos da ciência geográfica, como a exemplo de região, lugar e paisagem a partir de sua experiência de vivência no espaço taipuense.
\end{abstract}

Palavras-Chave: Ensino de Geografia. Estratégias didático-pedagógico. Regionalizar. Educando.

\begin{abstract}
\footnotetext{
${ }^{1}$ Mestrando Profissional em Geografia, UFRN, e-mail: jpviana25@yahoo.com

2 Doutora, IFRN-CNAT, e-mail: cristina.cavalcanti@ifrn.edu.br
}

This study proposes as a theme to show the importance of didactic-pedagogical strategies in the teaching of geography, through the activity: building and regionalizing the city of Taipu- RN under the eyes of the student. The purpose of the research, besides elucidating these strategies in the teaching of school geography, is in the construction of a project / class that seeks to understand the concept of region, through the regionalization of the city of Taipu - RN, but 
from images using experience of the student. For the development of the study, a bibliographic review was initially performed, followed by the "Research-tion" methodology during the application of the strategy at the Adão Marcelo da Rocha State School. In order to arrive at the results, it was necessary to analyze the current geography from a perspective of the National Curriculum Parameters of Geography (NCP), as well as the challenges in the current education; show the importance of pedagogical strategies in the teaching of school geography and then understand the value of the place as a human experience and experience, and finally, the strategic step by step: regionalizing the city of Taipu-RN from photographs under the gaze of the learner. As a result of the application of the strategy, it was possible to observe that the learners came to understand the concepts of geographic science, such as region, place and landscape from their experience of living in Taipu.

Keywords: Teaching Geography. Didactic-pedagogical strategies. Regionalize. Teaching.

\section{Introdução}

A presente pesquisa surge da necessidade do professor da geografia escolar atual em propor meios didáticos que facilitem o processo de aprendizagem do aluno com relação aos conceitos da ciência geográfica. Assim, o trabalho traz o seguinte tema: "Estratégias DidáticoPedagógico no Ensino da Geografia: Construindo e Regionalizando a cidade de Taipu- RN sob o olhar do educando". Visa o desenvolvimento de estratégias pedagógicas no que tange os aspectos basilares da ciência geografia, como a exemplo do conceito de região, que é um conteúdo curricular presente nas séries do $7^{\circ}$ ano do fundamental II e $1^{\circ}$ série do ensino médio. Com isso, o ensino de Geografia abre a possibilidade de estudo da relação homem-meio, possibilitando assim, melhor explicar a sociedade e sua organização no espaço. A geografia enquanto seu objeto de estudo, tem o espaço como o centro de todos os acontecimentos sociais, políticos e econômicos, onde a regionalização surge no contexto da necessidade do homem em demarcar e orienta-se dentro de uma unidade distinta.

Dentro desse contexto, o trabalho objetiva mostrar o desenvolvimento de uma estratégia didático-pedagógico no ensino da geografia escolar, através da construção da regionalização da cidade de Taipu-RN sob o olhar do educando.

Assim, a pesquisa está dividida em três seções, na primeira parte conhecendo os principais desafios da geografia escolar atual na educação brasileira, em seguida compreendendo a importância da utilização do lugar como meio didático e por fim, mostrar o desenvolvimento de uma estratégia pedagógica no qual objetiva regionalizar a cidade de Taipu $-\mathrm{RN}$.

\section{Fundamentação Teórica}


A educação escolar representa uma atividade de intenso trabalho, tendo início a base familiar e, mais tarde, a figura da escola no que tange o processo de formação social. O ensino é uma maneira de se chegar à aprendizagem, ou seja, o aluno não aprende se não obtiver um estimulo ou uma orientação acerca dos deveres da vida cotidiana. Sendo assim, é um norteador importante que vai moldando o discente ao longo de sua jornada escolar.

Dessa forma, a aprendizagem é um processo lento e gradual, através de um conjunto de fatores e ao longo dessa jornada, será possível quebrar barreiras, atravessar obstáculos e se reinventar. Cavalcanti (2006) aponta alguns questionamentos que são levantados para uma aprendizagem mais significativa, como:

\footnotetext{
O que é a Geografia escolar na atualidade? Como ela se realiza? Como o professor a constrói? Quais os desafios da prática do ensino da Geografia? Quem são os alunos da Geografia? Como são esses alunos? Como praticam a Geografia do dia-a-dia? Como aprendem Geografia na escola? Que significados têm para os alunos aprender Geografia? Que dificuldades eles têm para aprender os conteúdos trabalhados nessa disciplina? (CAVALCANTI, 2006, p. 66).
}

Assim, nas ciências escolares, em especial a Geografia, é possível ver o quanto as dificuldades estão presentes no dia a dia do professor e do aluno, que atinge diretamente o processo do ensino-aprendizagem do mesmo. É uma necessidade humana, mas a aprendizagem que estamos querendo explicitar é a aprendizagem escolar, que, é como assinala Libâneo (1994, p. 83), “[...] um processo de assimilação de determinados conhecimentos e modos de ação física e mental, organizados e orientados no processo de ensino". Ou seja, a aprendizagem escolar é um conjunto de fatores internos psicológicos, aliados com os acontecimentos externos, que assim, moldam, transformar e cria, diferentes acepções no processo do aprender.

Com isto, na Ciência Geográfica, a principal dificuldade encontrada no aprender, é aproximar a realidade para o chão da escolar, trazer aquilo visto no jornal e na televisão como exemplo prático nos conteúdos abordados, colocar em prática uma abordagem que tenha significado e com isso conseguir construir uma teia de conhecimento que possibilite a interpretação dos fatos. Ou seja, tornar o conteúdo e a aprendizagem significativos.

Assim, entramos novamente no dilema, onde não adianta, ter a melhor teoria de aprendizagem ou a melhor forma de ensinar, se o aluno não despertar o interesse em aprender. Mas, tem saídas, uma destas é criar meios e estratégias que consigam trazer o "querer em aprender', o “querer em participar', ou seja, o “querer a questionar”. Mas isso só será possível, 
quando se utilizem a realidade do educando como proposta norteadora, até porque, o espaço é o objetivo central da ciência geográfica.

Conforme elenca Castrogiovanni (2010), onde o objetivo principal de estudo em Geografia, continua sendo o espaço geográfico, assim, é entendido por nós “como um produto histórico, como um conjunto de objetos e de ações que revela as práticas sociais de diferentes grupos que vivem num determinado lugar, interagem, sonham, produzem, lutam e (re)constroem". Ou seja, o espaço é o local de todo o desenvolvimento das sociedades, nela que se interagem, cria e transforma. Uma estratégia pedagógica alicerçada nesta é possível criar uma aprendizagem significativamente vivencial.

Entretanto, não é simplesmente pegar uma estratégia didática e emprega-la, são necessários criar questionamentos que visem diagnosticar: será que a estratégia empregada aos discentes surtirá efeitos? Será que necessita de reformulações e adequações ao público-alvo. Sem dúvidas, cabe ao professor criar meios que proporcionem o fim destes paradigmas.

Sabemos que a realidade encontrada não é fácil, e muito menos estimulante, não iremos aprender de formar perfeita através de uma estratégia pedagógica, mas a prática na escola e na realidade vivida, trará as respostas.

Conforme pontua Pontuschka, acerca das dificuldades encontradas no cotidiano do professor em sala de aula.

Todavia, diante de situações que geram debates, que podem deixar o professor inseguro em suas respostas, em geral, os mesmos evitam prolongar muito o assunto, e, com isso, vetam o aluno de falar, de perguntar e expor sua posição sobre o tema em pauta, preferindo levar para a sala de aula as respostas prontas para perguntas que nem se quer foram feitas (PONTUSCHKA, 2007, p. 13).

O que se tem, é um educando fortemente "armado" de informações de forma demasiada, sem filtro, ou processo de problematização no que tange discutir um determinado fenômeno. Entretanto, o professor, deve-se utilizar dessas informações, distorcendo e remodelando conjuntamente com os discentes.

Conforme elenca Pontuschka (2000), não é possível pensar no ensino e a aprendizagem da geografia sem estar interligado com o contexto e situação escolar, pois a geografia tem um instrumento valioso de elevar a criticidade dos alunos, quebrando então a tendência secular da escola como algo tedioso e desligado do cotidiano.

Essa ocorrência de dificuldades está relacionada à maneira como são conduzidas as práticas didáticas metodológicas relacionadas a geografia escolar. Existe um grande 
distanciamento, que não perpassa os muros da escola. Claro que não devemos esquecer-nos das situações difíceis enfrentadas diariamente pelos professores, mas esta figura importante para a sociedade e especificamente para o aluno deve buscar meios e alternativas para transformar e superar a realidade do contexto atual

A esse respeito, Kaercher (2009) diz em seu postulado "Desafios e Utopias no Ensino da Geografia", que o ensino continua desacreditado. Os educandos no geral não têm mais paciência para ouvir os professores. Assim é preciso que o aluno perceba qual a importância do seu espaço na constituição enquanto ser individual e integrante de uma sociedade. Sendo assim, a necessidade de considerar o saber e a realidade do aluno como referência para o estudo do espaço geográfico.

As dificuldades encontradas na geografia não são únicas, pois também ocorre em todas as demais ciências escolares, onde se tem repensado o seu papel do professor, na sociedade, pois passa a exigir, cada vez mais, por uma educação voltada à formação da cidadania, e que consiga fazer a ponte teoria - escolar, e prática- social. Como coloca Andrade (1987, p.17):

[...] Como a Geografia é uma ciência que tem relacionamento com uma série de ciências afins, é natural que entre ela e as outras ciências se desenvolvam áreas de conhecimento intermediário, ora como ramos do conhecimento geográfico, ora como ramos do conhecimento de outras ciências que se tornaram ou tendem a tornar-se novas ciências a serem pragmaticamente catalogadas.

Sendo assim, existem dificuldades e barreiras a serem quebradas na prática docente escolar. As indagações surgidas servirão de base na aprendizagem, no que diz respeito em "sempre bater na mesma tecla": trazer para os discentes algo significativo e construtivo, tendo os educandos como principal fio condutor no processo de ensino e aprendizagem.

Em relevância, o professor diante das dificuldades encontradas na geografia escolar, tem o dever de propor novos meios e soluções, através de estratégias que busquem no aluno uma motivação de continuar a aprender e que o professor seja, neste processo, o mediador do ensino/aprendizagem de uma geografia escolar mais significativa e real.

\section{Metodologia}

A estratégia didático-pedagógica que será demonstrada aqui, se desenvolveu através de uma oficina/aula aplicada na Escola Estadual Adão Marcelo da Rocha, na turma do $1^{\circ}$ ano "B" e que teve como denominação "Regionalizando a cidade de Taipu a partir da vivência do educando". Teve como objetivo colocar em prática o objeto de nossa pesquisa, ou seja, a 
construção da regionalização da cidade de Taipu, a partir do "olhar do educando".

Desse modo, buscou-se construir uma compreensão do espaço de expressão e vivência por parte dos alunos, no que tange o conteúdo de "Regionalização do espaço geográfico".

Para o desenvolvimento do estudo, inicialmente foi realizada uma revisão bibliográfica em obras de autores como: Ausubel, Callai, Cavalcanti, Castrogiovanni, Freire, Pontuschka, Tuan e dentre outros. Em seguida foi utilizado a metodologia "Pesquisa-ção" que segundo Thiollent (1985, p. 14) é "...um tipo de pesquisa com base empírica que é concebida e realizada em estreita associação com uma ação ou com a resolução de um problema coletivo e no qual os pesquisadores e participantes representativos da situação ou do problema estão envolvidos de modo cooperativo ou participativo."

\section{Resultados e Discussão}

A estratégia didático-pedagógica é composta por três passos metodológicos com suas respectivas subcategorias. Nos passos a seguir será detalhado de forma processual como se deu o planejamento, o primeiro contanto com a turma; a elaboração da oficina/aula; sua aplicação e pôr fim a culminância do projeto e avaliação.

Passo 01: Diagnóstico situacional: Esta primeira etapa é direcionada à realização do diagnóstico no local de intervenção, através de um pequeno questionário prévio, contendo as informações sobre a geografia local.

O questionário, denominado "diagnóstico situacional”, serve de base referencial como forma de avaliação dos discentes acerca do conteúdo a ser trabalhado em sala de aula, muito além, também tem como propósito saber o nível de alfabetização geográfica do alunado, e que servirá de base para a construção dos passos seguintes.

As questões definidas neste diagnóstico são relacionadas a duas etapas: a primeira com questões diretas acerca do conteúdo a ser trabalhado, que neste caso de exemplificação é o conteúdo curricular "regionalização", bem como, questionamentos gerais sobre esse conhecimento. A segunda etapa, tem por objetivo proporcionar uma avaliação sobre o lugar de vivência, relacionando ao conteúdo a ser abordado, neste caso, a cidade de Taipu-RN e seus aspectos geográficos.

A estratégia pedagógica aqui utiliza a cidade de Taipu-RN como local referencial e respectivamente a turma do $1^{\circ}$ ano "B" da Escola Estadual Adão Marcelo da Rocha, como local 
de intervenção. A intervenção do passo I ocorreu no dia 22 de maio, no turno vespertino, com a participação de um total de 28 discentes.

A partir da observação dos dados da parte I do diagnóstico situacional, o que nos "saltam os olhos" é referente ao questionamento sobre o que venha ser regionalização enquanto conceito, onde nenhum discente conseguiu responder ou pelo menos, tentar responder tal indagação.

Ao contrário disto, os dois questionamentos seguintes obtiveram um maior percentual de acertos, visto que a propostas dessas duas assertivas eram relacionadas ao nível de alfabetização geográfica, entretanto o quesito dois ainda mostra um dado bastante corriqueiro acerca da dúvida/informação sobre a quantidade de regiões do Brasil.

$\mathrm{Na}$ etapa II do diagnostico, em que objetiva saber o conhecimento dos alunos sobre a cidade de Taipu-RN em uma visão geográfica, teve como primeiro questionamento sobre a "localização da cidade no Estado do Rio Grande do Norte" em que 17 alunos responderam a afirmação "região do mato grande", por ser uma questão aberta poucos alunos responderam a assertiva. O segundo questionamento desta etapa foi relacionado aos municípios que fazem limites com a cidade, como pode ser observado no gráfico a seguir:

Neste quesito, obteve um grande percentual de resposta, visto pela facilidade da questão e por ser o município mais conhecido que limita a cidade de Taipu-RN. Entretanto, ainda houve muitas dúvidas relacionas as demais afirmativas, requerendo do aluno uma melhor compressão acerca dos limites municipais.

Nesta etapa II, observa-se que o resultado geral apresenta um percentual "bom", entretanto esses três questionamentos foram os que mais geraram dúvidas entre os alunos, sendo necessário sucessivas interpretações, principalmente para o quesito seis, onde foi requerido do aluno, uma visão aérea da cidade, acerca da sua localização cartográfica.

Passo 02: Aplicação da Oficina/Aula: Nesta etapa é dividido em três subseções: I Aula introdutória sobre regionalização e a cidade de Taipu; II - Conhecendo a atividade e definido as temáticas e III - Aula de campo temática e elaboração dos cartazes fotográficos.

Na primeira parte, foi destinado a explanação conceitual do que é regionalização, ou seja, o principal objetivo era correlacionar o conteúdo curricular do livro didático utilizado pelos alunos, acrescentando algumas informações e atividades práticas.

Observa-se que de início introdutório, foi necessário compreender o conceito de regionalização, entretanto havendo ainda a importância de indagar aos alunos um 
questionamento do colocado no diagnóstico e que não foi respondido por nenhum destes sobres "o que é regionalizar".

Logo, de forma conjunta com o livro didático e respectivamente com informações do IBGE e outras fontes para que se chegasse algo mais objetivo, auxiliando assim, no processo de aprendizagem. Ainda no desenvolvimento do conceito de regionalizar, foi criado uma atividade prática, onde tem por objetivo fazer o aluno regionalizar pequenos quadrados a partir de determinadas características previamente colocadas. Com isso, mostrando na prática o conceito base do que é regionalizar.

Na segunda parte da aula introdutória do passo II, foi destinado a conhecer a cidade de Taipu-RN geograficamente, conhecendo primeiramente seu fator histórico, no que colaborou para o desenvolvimento da cidade, bem como, sua configuração geográfica atual. Para isso, foi mostrado alguns acontecimentos importantes, como a construção da igreja católica no início do município, quando ainda era povoado da cidade de Ceará-Mirim.

A importância da estação ferroviária que fez a cidade crescer economicamente e a construção do hospital municipal que surgiu como uma espécie de atração residencial e demográfica para a parte "alta" da cidade como é denominado pela a população. Neste momento, conhecer a cidade de Taipu, por meio de sua geografia, é de extrema importância para o desenvolvimento da estratégia, pois é neste espaço que seria aplicado os próximos passos. Assim, uma parte central nesta explanação, foi o mapa da cidade de Taipu - RN, dando a possibilidade analise do discente, bem como, sua localização sob este território.

O mapa da cidade de Taipu - RN, mostra-se como proposta no conhecimento cartográfico do aluno, sob seu espaço de vivência diária, saber se localizar sob pontos referencias, compreender o relevo local, o desenvolvimento da cidade (demográfica e residencial).

Assim, foi possível os discentes analisarem a imagem de satélite da cidade de Taipu RN com a finalidade de compreender os pontos referenciais da cidade, isto é, aqueles que poderíamos alocar como marco referenciais na localização geográfica da cidade. Logo, a partir da leitura geográfica do mapa, definimos os seguintes pontos referenciais: a igreja católica como ponto referencial (SUL); a estação ferroviária como marco zero $\left(0^{\circ}\right.$ ou central); e o pórtico da entrada da cidade como ponto referencial (NORTE).

Desse modo, foi mostrado o passo a passo da atividade, onde cada etapa seria desenvolvida de forma conjunta: 
I: conhecendo a proposta do projeto que seria regionalizar a cidade de Taipu - RN, através de cartazes fotográficos;

II: definindo as temáticas que iriam regionalizar a cidade de Taipu - RN, sendo (política, economia, social, histórica), estas foram escolhidas pelos os próprios discentes;

III: definição de um cronograma para a construção do projeto, do estudo do meio e da culminância/apresentação dos trabalhos finais.

Para a construção dos mapas temáticos, seria necessário obedecer a alguns critérios para sua construção e respectivamente na sua leitura cartográfica da regionalização da cidade de Taipu - RN, sendo:

$\checkmark$ Cada mapa temático deverá ter uma cor diferente, incluindo legendas símbolos;

$\checkmark$ Em todos os mapas terão que apresentas os três pontos referencias definidos nos passos anteriores (N - Igreja Católica; $0^{\circ}$ - Estação Ferroviária; S - Pórtico da cidade).

$\checkmark$ Ao lado de cada fotografia/imagens, deverá conter sua localização e uma breve contextualização;

$\checkmark$ Deverá utilizar setas que indique o posicionamento dos locais fotografados sob o mapa, com a finalidade de se ter uma localização cartográfica em relação aos pontos referenciais.

Com a definição dos temas e a exemplificação dos cartazes fotográficos, a turma foi dividia em quatro grupos, com a finalidade de irem para campo, para trazerem para a próxima aula fotografias concernentes a cada temática definida.

Como próximo aspecto desta estratégia, foi a construção dos cartazes fotográficos temáticos. Onde foi um momento conjunto no desenvolvimento e seleção de que fotografias iriam ser colocadas e o porquê. Vale ressaltar, que durante as fotografias pela a cidade, houve uma pesquisa com indivíduos característicos deste lugar, bem como, pesquisas informacionais em órgãos como IBGE, Museu Câmara Cascudo e Prefeitura Municipal de Taipu.

Para a construção dos cartazes foram necessários os seguintes materiais:

$\checkmark$ Cartolina em cor única (utilizada na estratégia: cor de rosa);

$\checkmark$ Piloto para nomes e informações;

$\checkmark$ Cola;

$\checkmark$ Um mapa da cidade de Taipu - RN colorido (pode ser desenhado o mesmo);

$\checkmark$ Fotografias coloridas. 
Em linha gerais, neste passo tem como principal objetivo a construção propriamente dita dos cartazes fotográficos, entretanto, traz consigo a união, o trabalho em equipe, assim como, a importância do estudo do meio, a partir que o aluno compreende os conceitos geográficos e ao sair pelos espaços territoriais da cidade, passa a ter uma nova ótica que antes vistas como normais e ser utilidade, mas agora, com um olhar crítico e analítico.

Passo 03 Apresentação e finalização: Destinado a finalização da oficina/aula, através da culminância dos cartazes fotográficos e avaliação de todo o processo com os discentes. Neste último passo, faz-se a apresentação dos cartazes fotográficos, onde os discentes puderam mostrar seus projetos, as seleções das imagens, o porquê de cada fotografia, a sua importância no espaço taipuense e principalmente a compreensão destas locais com o mapa.

Houve um momento rico de conhecimento e troca de informações sobre os diversos locais visitados. A exposição dos cartazes fotográficos pôde mostrar diferentes visões do espaço e ao mesmo tempo as transformações dos lugares, no que tange a temática histórica. Nas figuras a seguir, os cartazes construídos pelo os alunos em conjunto com o professor.

Figura 1: exposição dos cartazes fotográficos

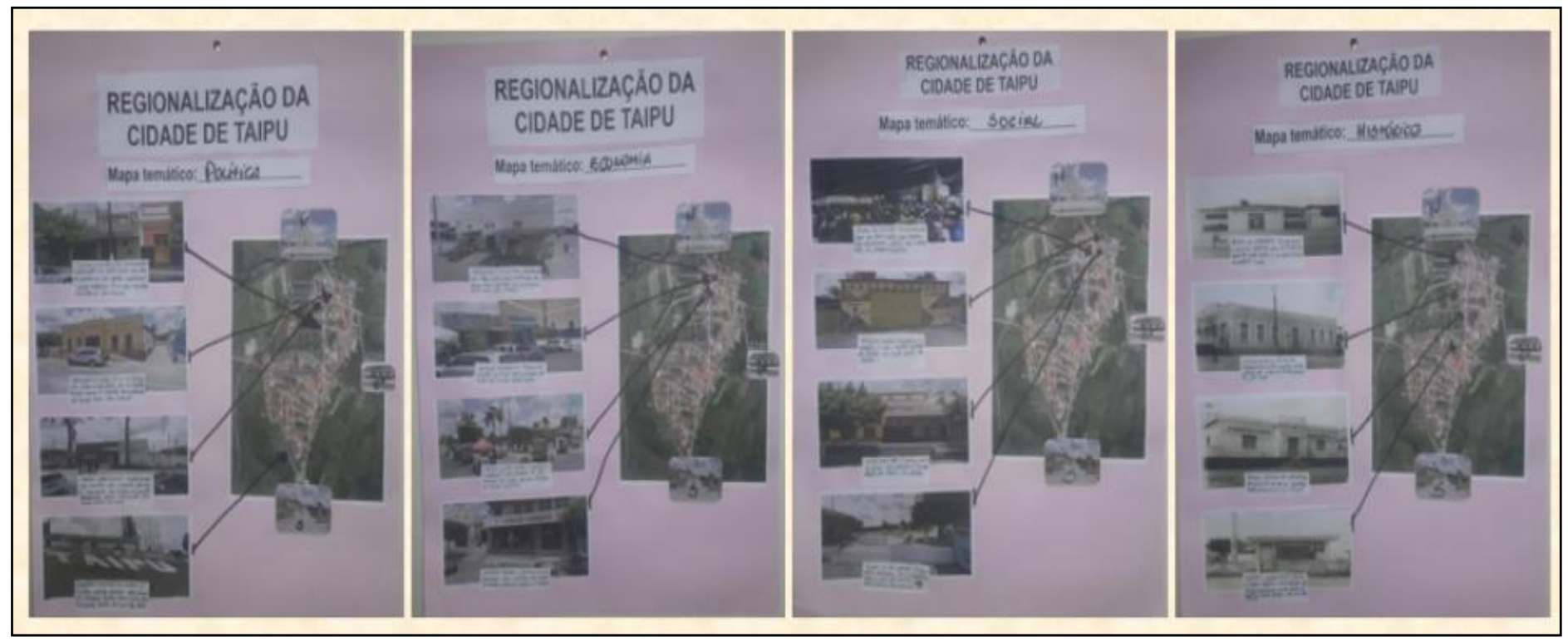

Fonte: acervo do autor, 2018.

Como forma de avaliação da estratégia aplicada, foi criado um questionário objetivo com o intuito de ter um "feedback" com relação a compreensão dos alunos perante o desenvolvimento do projeto. Onde $89 \%$ dos alunos responderam entre bom e ótimo a estratégia pedagógica. Além disso, elencaram algumas afirmações acerca de sua aprendizagem. "Aprendi com a aula do professor, pude conhecer a minha cidade, criei um olhar sobre os espaços que ando todos os dias e nunca tinha reparado o porquê de estar ali” (Aluno I do 1 ano B). "De 
início estava um pouco perdido sobre o conceito de região, mas quando, fiz a regionalização no mapa de Taipu, compreendi o que é e para que serve" (Aluno II do 1 ano B). "Sair com meus amigos pela a cidade de Taipu e fotografa foi muito interessante, pois conheci a história e a geografia do meu município com outros olhos e que agora, geográficos” (Aluno III do 1 ano B).

Assim, observa-se que a estratégias pedagógica, em que regionaliza a cidade de Taipu - RN conseguiu atingir o objetivo proposto, muito além da alfabetização geográfica relacionado ao conceito de região, lugar e dentre outros, mas da importância dos educandos terem um novo olhar sob o território de vivência e que seu lugar no mundo tem uma história geográfica em seu espaço.

\section{Conclusões}

Depreende-se que a educação brasileira no contexto atual está em um processo de transformações e, como vimos, necessita do professor uma nova postura perante os acontecimentos do mundo e no espaço escolar. Através dos objetivos propostos nesta pesquisa, devemos elucidar alguns pontos importantes no decorrer deste trabalho.

Desta maneira, observa-se que os objetivos propostos foram alcançados com êxito, mas não foram de forma rápida ou "mágica", mas de uma construção dialogada, planejada e direcionada para a realidade dos educandos e de suas perspectivas sócio educacionais. Não foram fáceis, ter a atenção e principalmente a participação dos alunos no desenvolvimento desta estratégia. Foi requerido um estudo prévio da alfabetização geográfica, através do diagnóstico situacional, que foi de grande importância para a conhecer os saberes geográficos dos alunos. Entretanto, com um planejamento e uma pesquisa prévia, é possível construir estratégias que possibilitem quebrar essas barreiras que os professores de todas as ciências educacionais encontram no dia a dia. É necessário assim, que o professor tenha primeiramente a humildade de uma autocritica, pois nem sempre sairá como planejado, sempre haverá um desvio no caminho, ou seja, requer que o professor tenha sempre um plano "a", "b", "c" (...), para que o ensino seja contínuo e a aprendizagem não sofra barreiras ao longo do percurso.

Em linhas gerais, podemos dizer que o ensino é como um automóvel recém-fabricado que dará suporte, e a aprendizagem é para aqueles que queiram pilotar, isto é, esse processo é feito de forma conjunta e mútua, entre a figura do professor como mediador e do aluno como principal objetivo da aprendizagem. 
Assim, a estratégia didático-pedagógico aqui desenvolvida é apenas um passo mais alto a ser dado, é apenas uma forma de mostrar que é possível, a partir da análise das problemáticas em sala de aula, da realidade do aluno e das suas dificuldades no processo do aprender. Criar meios que propiciem a aprendizagem do educando de forma que estes atores sociais sejam participantes do processo de ensino e da aprendizagem.

Em suma, espera-se que esse meio didático pautado na regionalização do lugar de vivência, sirva como um contributo para futuros professores aplicarem na realidade de suas escolas, sejam elas na perspectiva de uma rua, bairro, cidade, estado. Mas que utilizem a vivência do aluno, a sociedade que os rodeiam, o conhecimento que eles têm sobre o espaço geográfico e que com tudo isso traduzam para um ensino geografia significativo e humano.

\section{Referências}

AUSUBEL, David Paul, NOVAK, Joseph D., HANESIAN, Helen. Psicologia Educacional. Rio de Janeiro: Interamericana, 1980.

ANDRADE, E. G. C. Família, escola e a dificuldade de aprendizagem: intervindo sistematicamente. Psicologia Escolar e Educacional, Campinas V. 7. N. 2 p.171-178, dez 2003.

BRASIL. Secretaria de Educação Fundamental. Parâmetros curriculares nacionais: geografia / Secretaria de Educação Fundamental. Brasília: MEC/ SEF, 1998.

CASTROGIOVANNI, Antônio Carlos. Ensino de Geografia. Práticas e Textualizações no Cotidiano. $7^{\text {a }}$ Ed. Porto Alegre: Mediação, 2009, P. 101

CALLAI, Helena Copetti. A Geografia e a Escola: Muda a Geografia? Muda o Ensino? Revista Terra Livre, n. 16. (p. 133-152). São Paulo, 2004.

CAVALCANTI, Lana de Souza. Ensino de Geografia e Diversidade: construção de conhecimentos geográficos escolares e atribuição de significados pelos diversos sujeitos do processo de ensino. São Paulo: Contexto, 2006.

FEIRE, Paulo. Pedagogia da Autonomia: saberes necessários à prática educativa. Rio de Janeiro: Paz e Terra, 2003.

KAERCHER, Nestor André. O gato comeu a Geografia Crítica? Alguns obstáculos a superar no ensino-aprendizagem de Geografia. In: PONTUSCHKA, Nídia N. e OLIVEIRA, Ariovaldo U. (orgs.). Geografia em Perspectiva: ensino e pesquisa. São Paulo: Contexto, 2009.

PONTUSCHKA, Nídia N. Geografia, Representações Sociais e Escola Pública. Terra Livre. São Paulo, n. 15, p. 145-154, 2000. 
PONTUSChKA, Nídia. N.; PAGANELli, T; CACETE, N. Para Ensinar e Aprender Geografia. 1 ${ }^{\text {a }}$ Ed -São Paulo: Cortez, 2007. 